\title{
O que os Pais Falam Sobre a Mesada: Função da Mesada para Pais de Diferentes Rendas Econômicas
}

\author{
Irani Lauer Lellis ${ }^{* a}$, Celina Maria Colino Magalhães ${ }^{a}$ \& Iani Dias Lauer Leite ${ }^{b}$

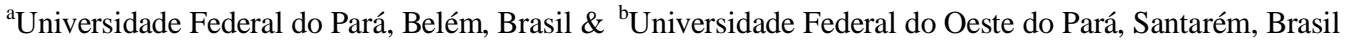

\begin{abstract}
RESUMO
A prática de dar mesada é utilizada por vários pais em diferentes partes do mundo e pode contribuir na educação econômica de crianças. Este estudo objetivou investigar os propósitos da mesada com 32 pais de rendas variadas. Utilizou-se a técnica de grupo focal e o software Alceste para analisar os dados. Os resultados envolveram duas classes relacionadas ao processo de utilização da mesada. Essas classes abarcaram aspectos relacionados a função socializadora e educativa da mesada, servindo como instrumento de recompensa, mas algumas vezes fomentando maus hábitos nos filhos. A justificativa dos pais sobre a quantia de dinheiro que se deve dar aos filhos e quando devem parar de dar mesada também foram destacados.
\end{abstract}

Palavras-chave: mesada; socialização econômica; práticas parentais.

\section{ABSTRACT \\ What Parents Say About the Allowance: Function of the Allowance for Parents of Different Economic Incomes}

The practice of giving allowance is used by several parents in different parts of the world and can contribute to the economic education of children. This study aimed to investigate the purposes of the allowance with 32 parents of varying incomes. We used the focus group technique and Alceste software to analyze the data. The results involved two classes related to the process of using the allowance. These classes have covered aspects of the role of socialization and education allowance, serving as an instrument of reward, but sometimes encouraging bad habits in children. The justification of the fathers concerning the amount of money to be given to the children and when to stop giving allowance were also highlighted.

Keywords: allowance; economic socialization; parenting practices.

Educar uma criança, acompanhando os vários aspectos que envolvem o seu desenvolvimento, tem sido preocupação de muitos pais ao redor do mundo e tem despertado o interesse de vários estudos. A forma como os pais cuidam dos filhos são importantes fontes de influência no desenvolvimento da criança, uma vez que o desenvolvimento acontece neste contexto. Acredita-se que os processos relacionais existentes entre pais e filhos são situações complexas, influenciando e sendo influenciadas pelo contexto imediato de inserção da família e por situações que fazem parte da organização social e histórica da comunidade (Bron- fenbrenner, 1996; Harkness \& Super, 1996). Segundo Bronfenbrenner (1996), as interconexões existentes nos vários níveis que compõem o ambiente ecológico são fortes forças que afetam o crescimento psicológico, o desenvolvimento.

A relação entre o desenvolvimento infantil e contextos culturais pode ser verificada no modelo proposto por Harkness e Super (1992) chamado de nicho de desenvolvimento. Segundo tais autores, esta é uma maneira interessante de se estudar a formação do microambiente da criança. Este modelo inclui três subsistemas: o primeiro envolve o contexto físico e social da

\footnotetext{
Endereço para correspondência: Irani Lauer Lellis - iranilauer@gmail.com.
} 
vida da criança (onde a criança vive). O segundo envolve os costumes e práticas que são culturalmente reguladas referentes ao cuidado e criação da criança (formas de cuidados básicos, formas de educar a criança) e o terceiro, refere-se à psicologia dos agentes socializadores, aqueles que cuidam das crianças, ou seja, refere-se à psicologia dos cuidadores (crenças, valores e expectativas de mães em relação aos filhos). A partir deste modelo é possível considerar a existência de uma dinâmica entre a psicologia dos cuidadores e suas práticas, com o desenvolvimento infantil.

Abordagens como a teoria ecológica e o co-construtivismo fazem referência às mútuas influências que existem entre o indivíduo e o contexto (Bronfenbrenner, 1996; Valsiner, 2000). Na teoria ecológica a relação entre mãe e filho é de interinfluência, assim como a relação de outras pessoas que podem não estar presentes no ambiente físico imediato. A investigação desta relação mãe-filho poderá esclarecer as mudanças que ocorrem no desenvolvimento da criança, nos adultos que cuidam dela e no ambiente em que ela está inserida. O co-construtivismo aponta que o desenvolvimento individual é conduzido pela organização cultural do ambiente, sendo determinado pela relação entre o organismo e o ambiente que o rodeia, propondo que os processos de desenvolvimento devam ser analisados dentro do contexto cultural em que ocorrem (Valsiner, 2000).

Lordelo et al. (2000) investigaram o ambiente doméstico de 45 mães e seus filhos de classe pobre e média, em termos de responsividade às demandas da criança no contexto de crenças e práticas como sistema cultural de criação de filhos. Utilizou instrumentos como entrevistas e questionário para avaliar atitudes em relação à maternidade, autonomia da criança e nível de responsividade materna. Os principais resultados indicaram que as mães possuíam a tendência de pensarem a maternidade e a educação de seus filhos conforme o contexto em que vivem e de se comportarem de diferentes maneiras, segundo suas condições de vida. Verificou-se que as mães compartilhavam algumas crenças e valores, mas enquanto grupo, se diferenciavam em relação a modelos de criação, que seriam os mais susceptíveis às influências do ambiente imediato. Os resultados apontaram ainda para uma articulação entre as crenças referentes aos sistemas culturais em que são construídas e mantidas, bem como as práticas de cuidado à criança.
Apesar das diferenças entre modos de criação, todos os pais possuem crenças em relação à melhor maneira de cuidar e educar seus filhos, incluindo as crenças em relação à maneira que podem educar seus filhos economicamente. As crianças entram em contato com o dinheiro cedo. Esse contato pode acontecer de forma direta ou indireta. Acontece de forma indireta quando veem seus pais comprando ou vendendo coisas e de forma direta quando recebem mesada. Muitos pais dão mesada aos filhos para que estes tenham a oportunidade de aprender as transações ligadas ao uso do dinheiro com responsabilidade. Sendo o dinheiro a base de todas as ações econômicas, o entendimento do seu significado é um pré-requisito para o entendimento de outros conceitos como o crédito e o lucro. Portanto, o manejo do dinheiro pode auxiliar na compreensão dos demais conceitos econômicos (Furnham \& Argyle, 1998).

Feather (1991) investigou o propósito do dinheiro dado aos filhos e entrevistou 133 famílias na Austrália. Os resultados mostraram que os propósitos para o dinheiro dado aos filhos estavam relacionados ao treinamento da independência da criança, isto é, a preocupação dos pais de que seus filhos desenvolvam um senso de responsabilidade, concernente a saberem lidar com o dinheiro de forma responsável, preparando-os assim para o mundo adulto. Outro motivo enfatizado pelos pais para darem dinheiro aos filhos relacionou-se a necessidade da criança, isto é, as demandas financeiras de seus filhos.

Autores como Baele e Vlerick (2000), Furnham e Thomas (1984) tem se dedicado a estudar temas da psicologia econômica. Ambos investigaram as estratégias empregadas pelos pais para darem mesada aos seus filhos. Verificou-se nestes estudos que as estratégias educativas em torno da educação econômica e mais especificamente em torno da mesada, variam em decorrência de fatores, como sexo e idade dos pais, escolaridade e renda econômica.

A relação entre os indivíduos e a economia é a área de estudo da Psicologia Econômica que busca compreender de que maneira a economia influencia a vida dos indivíduos e de que formas os indivíduos interferem na economia, usando para isso instrumentos da Psicologia (Moreira, 2000). A relação da criança com os aspectos econômicos do mundo é foco da Socialização Econômica, uma linha de estudos da Psicologia Econômica. Mas também é tema de interesse da Psi- 
cologia do Desenvolvimento, representa, portanto um ponto de convergência entre a Psicologia Econômica e a Psicologia do Desenvolvimento. Ambas as áreas têm trazido contribuições relevantes para o melhor entendimento de como a criança relaciona-se com o mundo econômico.

A compreensão das várias questões pertinentes à vida econômica é diversa entre crianças e adultos. Os próprios comportamentos econômicos de ambas as classes é diferenciado. Apesar de crianças não terem um entendimento pleno do mundo econômico e mesmo em algumas fases elas apresentarem compreensão incorreta deste mundo, elas se comportam economicamente e influem nas decisões econômicas dos adultos próximos a elas. Para averiguar essa afirmativa, basta observar o aumento dos investimentos em pesquisa em consumo infantil (Cram \& Ng, 1999).

O consumo infantil representa a possibilidade de criar produtos e serviços voltados para as necessidades específicas da criança; uma força de influência importante nas decisões de compra da família, uma vez que elas falam de seus desejos e necessidade e convencem muitas vezes os adultos a realizarem a compra, causando nos pais uma forte tendência a consumir mais ou experimentar certa classe de produtos (Ballvé, 2000). As crianças influem nos comportamentos econômicos dos adultos cuidadores, mas também estes influenciam a socialização econômica das crianças e seus comportamentos econômicos, mediante as crenças e práticas econômicas desenvolvidas por eles. Conforme afirmam Cram e Ng (1999) investigar o papel dos pais no desenvolvimento das habilidades, orientações de comportamento, conhecimento e atitudes relacionadas ao mundo econômico é fundamental no preparo das crianças para participarem do mundo dos adultos.

Diante do exposto, este estudo faz parte da investigação desenvolvida por Lauer e Magalhães (2007) que objetivou investigar as crenças e práticas dos pais sobre a mesada. Através da técnica de grupo focal trinta e um pais de variadas rendas contribuíram para o estudo. Os principais resultados demonstraram uma busca dos pais de justificar a mesada como estratégia educativa e de a considerarem como um fator de integração social. Os resultados mostraram ainda a existência de fatores relacionados aos componentes da mesada, como frequência e regularidade, valor e necessidade dos filhos. Pretende-se aqui elucidar o papel da mesada como estratégia educativa.

\section{MÉTODO}

\section{Participantes}

Fizeram parte do estudo trinta e um pais, entre as idades de 27 a 53 anos, sendo 13 do sexo masculino e 18 do sexo feminino, com filhos entre 6 e 16 anos, com renda econômica familiar entre $\mathrm{R} \$ 300,00$ a $\mathrm{R} \$ 10.000,00$, exercendo diferentes ocupações profissionais na cidade de Belém/PA. Para a seleção da amostra dos grupos focais foi utilizado como critério a localização de moradia dos participantes (pais moradores de periferias e pais moradores de bairros mais nobres), que foram distribuídos em quatro grupos focais. Em todos os grupos focais havia pais de ambos os sexos, de diferentes idades, escolaridade, número de filhos, ocupações e renda variada. Na composição dos grupos focais intervieram outras variáveis que diziam respeito às características da técnica de grupo focal propriamente dita como no mínimo seis sujeitos por grupo e duração de no máximo uma hora e meia. Dos quatro grupos focais, dois grupos foram constituídos por pais que moravam em bairros pobres de Belém e que possuíam baixa renda econômica (Grupo 2 renda mínima $\mathrm{R} \$ 300,00$ e renda máxima $\mathrm{R} \$ 1.200,00$; Grupo 3 - renda mínima $\mathrm{R} \$ 500,00$ e renda máxima $\mathrm{R} \$ 1.300,00)$ e dois grupos com pais moradores de bairros nobres e com renda econômica mais elevada (Grupo 1 - renda mínima R $\$ 900,00$ e renda máxima $\mathrm{R} \$ 6.065,00)$.

\section{Procedimento de Coleta de Dados e Instrumento}

A coleta de dados foi realizada nos períodos da noite, iniciando às $19 \mathrm{~h} 30 \mathrm{~min}$, em quatro locais (interior de um bar, salão de recepção de um condomínio, duas salas de estar da residência de dois participantes) cedidos pelos participantes, sendo ambientes privativos. Para a coleta de dados foi utilizada uma folha de registro para os dados pessoais dos participantes e um guia de temas para o grupo focal. Os pais foram contactados pelo pesquisador que após se apresentar estendia o convite aos pais e pedia que estes indicassem algum conhecido da proximidade que possuísse filhos entre 6 e 16 anos e que tivessem acima de 21 anos. Em seguida o local e horário foram acertados. Os pais que fizeram parte do estudo dirigiram-se ao local previamente combinado, onde foi explicada a pesquisa e entregue a cada participante um Termo de Consentimento, em que se documentava sua disposição voluntária de participação no estudo. O Termo de Consen- 
timento constou do projeto apresentado ao Comitê de Ética em Pesquisa Envolvendo Seres Humanos do Núcleo de Medicina Tropical da Universidade Federal do Pará, o qual deu parecer favorável à pesquisa ( $\mathrm{N}^{\mathrm{o}}$ 062/2006-CEP/NMT).

A técnica de grupo focal pode ser utilizada em pesquisa exploratória, centrada na produção de conteúdos que coleta dados mediante as interações grupais que acontecem em discussões ao redor de um tema delimitado por um pesquisador (Gondim, 2002). O objetivo central do grupo focal é identificar percepções, sentimentos, atitudes e ideias dos participantes a respeito de um determinado assunto. $\mathrm{O}$ grupo focal visa a geração de ideias e opiniões espontâneas, sendo extremamente importante a participação de todos, porém sem coação (Bauer, Gaskell \& Allum, 2003).

Os quatro grupos focais foram conduzidos por um moderador e um observador. As discussões para ambos os grupos foram baseadas em um esquema semiestruturado, explorando o tema mesada. Os participantes expressaram suas opiniões sobre o tema, sendo as perguntas abertas, possibilitando o surgimento de novos questionamentos durante as discussões. Todos os grupos focais visaram averiguar as crenças e práticas dos pais em relação à mesada, além da existência de divergências, convergências e novos conceitos sobre o tema ainda não encontrados na literatura.

Os grupos focais tiveram duração de aproximadamente 60 minutos, sendo realizada uma sessão com cada grupo, perfazendo quatro sessões. Todas as discussões foram registradas em dois gravadores e transcritas posteriormente.

\section{Procedimento de Análise dos Dados}

A análise dos dados foi feita pelo software Alceste (Reinert, 1990), em sua versão 4.5. O programa Alceste analisa o corpus que é o objeto de estudo do pesquisador - um texto transcrito (entrevista, grupo focal, narrativas orais, entre outros), operando em quatro etapas de análise. Na primeira etapa o programa prepara o corpus, fazendo a fragmentação de palavras com base no seu radical léxico, verificando sua frequência e distribuição no texto, cria um dicionário de formas reduzidas, reconhecendo as unidades de contexto inicial (UCI) que correspondem às respostas de cada participante da pesquisa e separa das unidades de contexto elementares (UCE), que são segmentos que constituem o ambiente da palavra, respeitando-se a aparição no corpus de análise. Finalmente faz distinção entre palavras secundárias, como artigos, preposições e conjunções e palavras fundamentais para a análise como substantivos, verbos, adjetivos, isto é, termos que definem o ideário do sujeito. Na segunda etapa o programa classifica as UCE em função dos seus vocabulários e agrega-as de acordo com a frequência das formas reduzidas. A partir de matrizes de frequência, o programa cruza as formas reduzidas e as UCE, dando origem à Classificação Hierárquica Descendente.

Esta classificação consiste em repartir as UCE em função do seu vocabulário, de sorte que seja obtido o maior valor em uma prova matemática de associação interclasses, como o $X^{2}$. O mesmo procedimento é repetido com as classes obtidas, de modo que o vocabulário das UCE de todas as classes fique o mais homogêneo possível. Essa divisão de classes é mostrada pelo programa em forma de gráfico, chamado de dendograma. A terceira etapa descreve as classes de UCE escolhidas. O programa agrupa as classes de acordo com seu conteúdo léxico, permitindo-nos compreendê-las. Para Reinert (1990), essas classes podem ser interpretadas como noções de mundo ou como quadro perceptivo-cognitivo com certa estabilidade temporal. A última etapa é a dos cálculos complementares em que o programa escolhe as palavras e, por conseguinte, as UCE mais características de cada classe (Oliveira, Gomes, \& Marques, 2005; Ribeiro, M. S. A., personal communication, 2006).

\section{RESULTADO E DISCUSSÃO}

O corpus analisado reconheceu 548 unidades de contexto inicial (UCI), e verificou a ocorrência de 29.347 palavras, sendo 2.481 palavras diferentes no corpus, indicando uma frequência média de 12 ocorrências por palavra. Após a redução das palavras a suas raízes, obtiveram-se 2.161 palavras analisáveis (indicadores de sentido). Seguindo critério do Alceste, não foram consideradas palavras que possuíssem frequência inferior a três, posto que concerne ao critério estabelecido no cálculo do $\mathrm{X}^{2}$.

A análise hierárquica reteve 990 unidades de contexto elementar (UCE), sendo assim consideradas $71,71 \%$ do total de UCE do corpus (710 das 990 UCE), organizadas em cinco classes, que foram distribuídas em três eixos temáticos. Os resultados foram denominados genericamente, "cognição parental acer- 
ca da mesada" e são mostrados na Figura 1, que apresenta os conteúdos discursivos organizados em forma de um dendograma resultante da análise hierárquica descendente.

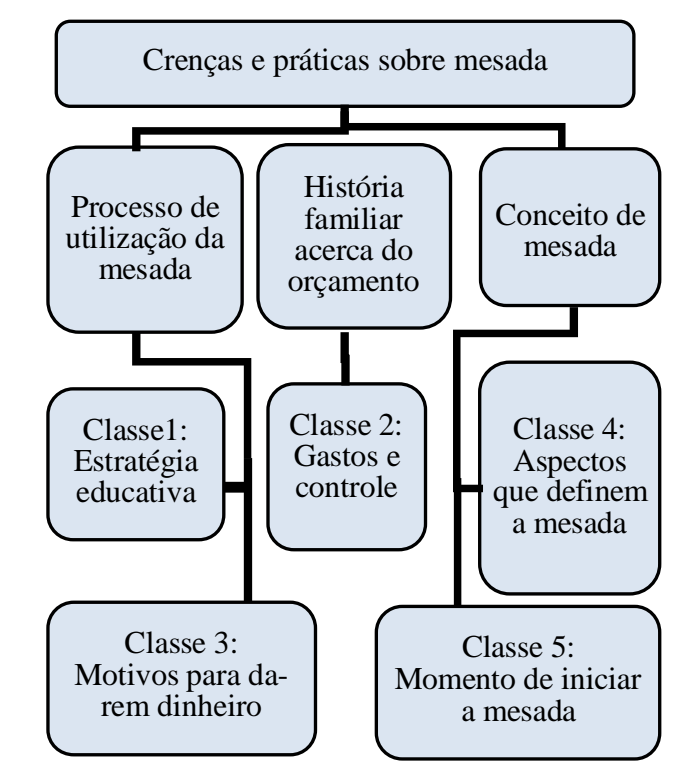

Figura 1. Dendograma da análise hierárquica descendente.

Observa-se nesse dendograma (Figura 1) que a produção discursiva foi distribuída em três eixos iniciais de textos denominados, respectivamente: "Processo de utilização da mesada" (primeira ramificação), "História familiar acerca do orçamento" (segunda ramificação) e "Conceito de mesada" (terceira ramificação). O eixo "Processo de utilização da mesada", desdobrou-se em duas classes, ambas referentes à visão dos pais em relação à mesada, guardando, portanto uma relação de proximidade temática entre si, apesar de focalizarem diferentes aspectos concernentes à mesada: classe 1 - Estratégia educativa e classe 3 - Motivos para darem dinheiro.

O segundo eixo: "História familiar acerca do orçamento", separou dos conteúdos restantes a classe 2 denominada: "Gastos e controle", que trata dos relatos dos pais acerca da sua própria história familiar com os seus pais. Nos relatos formados aparecem diferentes momentos, dos quais os participantes passam de ex- pectadores a membros ativos do controle orçamentário familiar.

O terceiro eixo denominado: "conceito de mesada", desdobrou-se em duas ramificações: "Aspectos que definem a mesada" (classe 4) e "Quando começar a dar mesada" (classe 5) e tratam de conteúdos ligados a definição de mesada e do momento para iniciar e parar de dar a mesada.

Como o presente estudo focaliza o tema mesada e sua função educativa, será discutida aqui, especialmente, a classe $1,3,5$, respectivamente denominadas "estratégia educativa"; "motivos para darem dinheiro" e "quando começar a dar mesada". Para cada uma das três classes de segmento de texto obtidas, apresentarse-á, na Figura 2, seu vocabulário (por ordem de frequência de ocorrência) e a indicação da significação da sua ligação com a classe. Serão também exemplificadas, as relações dessas palavras entre si, na forma de trecho de entrevistas utilizando as unidades de contexto elementar mais significativa de cada classe. 


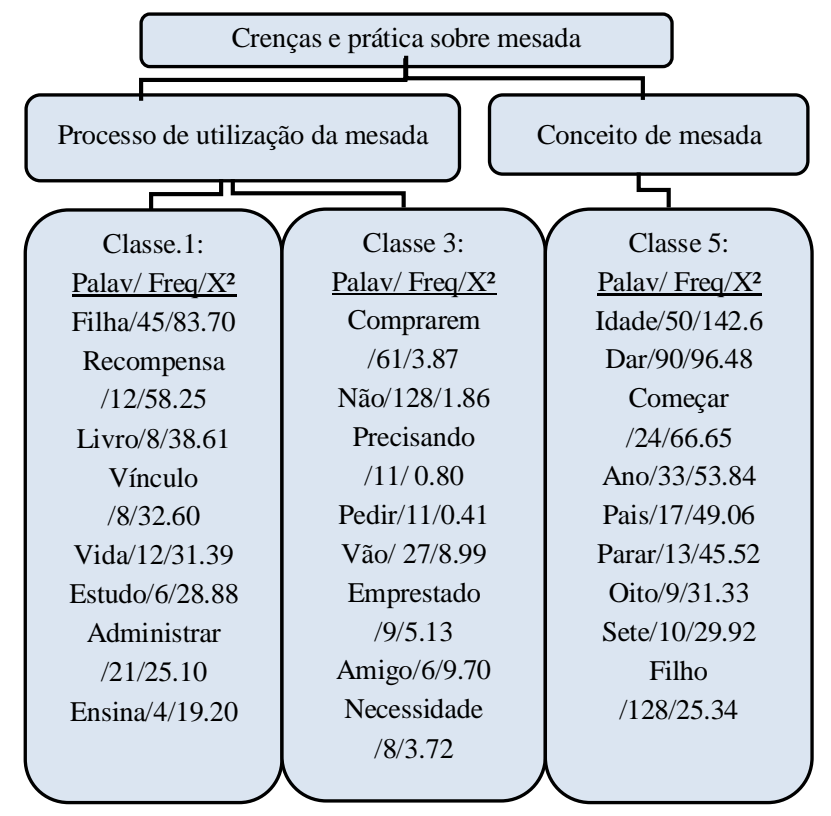

Figura 2. Detalhamento de dendograma de classes.

O primeiro conjunto de conteúdos isolados pelo software Alceste foi denominado "Estratégia Educativa". Esta classe organiza-se em torno do que os pais consideram ser a função e o propósito primordial da mesada. As UCE que mais contribuíram para a formação desta classe foram aquelas produzidas por pais que possuíam grau de escolaridade superior, um filho e com renda familiar acima de $\mathrm{R} \$ 3.001,00$. A análise das variáveis descritas nesta classe permite caracterizá-las como sendo associadas aos grupos focais de pais de renda média.

Nesta primeira classe, a importância da mesada como estratégia educativa é reforçada pela saliência das palavras referentes a aspectos que envolvem o processo educativo tais como livro, leitura, estudar, administrar, ensinando, aprendendo (ver Figura 2). O papel dos pais em relação à responsabilidade de educarem seus filhos indica a relevância da mesada na educação econômica dos filhos deste cedo, uma vez que sua função é ensinar a administração do dinheiro. A importância de tal ideia pode ser ilustrada a partir dos resultados gerados na terceira etapa do programa que mostra as UCE mais representativas dessa classe. Segue como exemplo a seguinte colocação:

A mesada é uma quantia que os pais dão para os filhos para que os filhos aprendam a administrar o dinheiro. A mesada serve para os filhos entenderem o que é ad- ministrar, como gastar o dinheiro e serem mesmo inseridos no mundo do dinheiro e da economia, saberem comprar e saberem o que fazer com o dinheiro. A mesada é a primeira forma de economia que existe na família. (Participante 4, mãe, 39 anos, 2 filhos, III Grau, renda de $\mathrm{R} \$ 5.800,00)$

Segundo os pais a mesada tem a função de ensinar e educar os filhos, ajudando-os no aprendizado da administração do dinheiro, servindo por vezes como instrumento de recompensa e como instrumento capaz de criar maus hábitos nos filhos. As respostas dos pais indicam que nesse grupo pensa-se que o propósito da mesada é a educação econômica, confirmando os estudos desenvolvidos por Lassarre (1996) sobre o papel educacional da mesada, destacando que a prática de dar mesada aos filhos é sinal de educação econômica dentro da família. Furnham (1999) em seus estudos sobre o tema também declara que os pais usam a mesada como um modo de socializar e educar as crianças. No presente estudo percebe-se que tanto os pais de renda média como os pais de baixa renda acreditam que a mesada é um instrumento que ajudará os filhos a aprenderem a administrar o dinheiro. Crença semelhante foi encontrada por Abramovich, Freedmar e Pliner (1996). Estes autores apontaram a mesada como facilitadora do desenvolvimento da competência monetária. 
Outra função observada da mesada e semelhantemente encontrada por Feather (1991) em seus estudos com famílias britânicas, diz respeito à preocupação dos pais sobre o desenvolvimento do senso de responsabilidade nos filhos, isto é, preocupação com o modo dos filhos lidarem com o dinheiro no futuro. Infere-se que os pais possuem a crença de que é preciso educar no presente, para que no futuro os filhos estejam preparados para relacionarem-se com o mundo adulto. Tal crença pode ser exemplificada na UCE que se segue:

O propósito da mesada é a criança desenvolver a responsabilidade, começar a administrar o dinheiro, porque se a pessoa cresce sem saber administrar o que ganha, ganha, gasta tudo de uma vez só porque não teve a noção de como administrar nada. (Participante 16, mãe, 30 anos, 1 filho, II Grau, renda de $\mathrm{R} \$ 1.200,00)$

Dentro da importância dada pelos pais a educação econômica, destaca-se um atributo chamado economia. Saber economizar, não permitindo que os filhos gastem tudo de uma vez é um fator bastante ressaltado pelos pais do presente estudo, uma vez que acreditam que se os filhos aprenderem a economizar o pouco que recebem, advindo da mesada, no futuro saberão economizar uma quantia maior.

Dentro desta perspectiva da mesada como estratégia educativa, verificou-se que os pais procuram não dar dinheiro de mesada aos filhos sem razão ou motivo e sim com um propósito definido. Um dos motivos para darem mesada aos filhos está relacionado às demandas financeiras da criança, motivo que também foi verificado por Baele e Vlerick (2000), Feather (1991) e Wronski (1999). Os pais adotam critérios, que podem ser chamados de critérios educativos para a decisão de atender a solicitação de dinheiro dos filhos. A UCE exemplifica este critério: Às vezes a minha filha me pede alguma coisa e eu fico pensando, eu fico pensando muito no que minha filha me pede porque é uma menina que não tenho do que reclamar faz tudo por merecer (Participante 18, mãe, 30 anos, 3 filhos, II Grau, renda de $\mathrm{R} \$ 600,00)$.

Os critérios para os pais atenderem as solicitações dos filhos são norteadas por questões que envolvem o bom comportamento dos filhos, que pode ser identificado na frase acima: "faz tudo por merecer", além do fator referente a necessidade do filho, isto é, se o mesmo está realmente precisando ou não. É possível observar que todos os pais que participaram do pre- sente estudo adotam critérios para avaliar as necessidades dos filhos quando estes lhe pedem dinheiro e ainda que o dinheiro dado deve ser empregado na compra de produtos que julgam ser adequados. Segue como exemplo a seguinte colocação:

Em relação a como gastar e quando gastar o dinheiro da mesada é uma questão que nós como pais precisamos orientar os nossos filhos, porque se você dá e não orienta você não está educando... O filho recebe o dinheiro fácil, gasta fácil de qualquer maneira, porque essas são as prioridades dos filhos. Se a criança for educada sem orientação não se tornará um bom adulto em termos financeiros, podendo não dar importância às coisas, com valores invertidos. $O$ simples fato de dar mesada não é uma educação financeira para a vida, eu tenho que dar a mesada e tenho que orientar como gastar... Os pais precisam perguntar o que os filhos acham que será o melhor. (Participante 31, pai, 41 anos, 2 filhos, renda de $\mathrm{R} \$ 4.500,00)$

Os pais igualmente demonstraram ainda que são a favor do estabelecimento de regras claras em relação aos itens que os filhos podem comprar com o dinheiro da mesada. Furnham (2001) também verificou este fato. Em outro estudo Furnham e Thomas (1984) verificaram que as mães britânicas mais que os pais são a favor de combinar com antecedência com a criança quais os tipos de itens que elas poderiam comprar. Neste contexto, os filhos possuem a decisão de escolher quais itens comprarão com a mesada, desde que esses itens se enquadrem as regras instituídas previamente pelos pais. A UCE seguinte exemplifica: Acho que os filhos podem gastar o dinheiro da mesada com o que quiserem, mas que seja dentro das orientações que a família estabelece. E se quebrar a orientação acho que os filhos devem ser punidos (Participante 1, pai, 33 anos, 1 filho, II Grau, renda de $\mathrm{R} \$ 3.200,00$ ). Resultado diferente foi encontrado nos estudos de Baele e Vlerick (2000), onde os filhos não possuíam muita participação na decisão de como gastar o dinheiro da mesada.

Um aspecto observado nas UCE desta classe refere-se à punição ressaltada pelos pais e vistas na UCE acima. As sansões dadas pelos pais aos filhos em relação à mesada (como perda da mesada ou diminuição da mesma) estão relacionadas à quebra das regras instituídas pelos pais sobre os itens que podem ou não ser comprados. Se o dinheiro da mesada for gasto com itens que os pais discordam ou se os filhos não cumprirem com as atividades determinadas pelos pais para 
que a mesada seja recebida, a mesma é retirada ou diminuída (sansões) como mostra a UCE a seguir: Se eu perceber que a minha filha faz mal uso do dinheiro eu corto a mesada imediatamente (Participante 1, pai, 33 anos, 1filho, II Grau, renda de R $\$ 3.200,00)$.

Furnham (2001) apresenta um ponto de discordância dos pais em relação à punição ou sansão. Em seus estudos verificou controvérsias relacionada retenção do dinheiro como castigo, diferente do presente estudo, em que todos os pais concordaram que o dinheiro deva ser retido, o que funcionaria como forma de disciplinar os filhos.

Com respeito à educação econômica observou-se a tentativa dos pais de vincular a mesada a alguma atividade doméstica ou escolar, sendo esta um instrumento de recompensa pelo cumprimento dos deveres e responsabilidades delegadas pelos pais, reforçando assim a ideia anterior de que a mesada também possui uma função de disciplinar, reforçando seu papel educacional.

A vinculação da mesada a alguma atividade não foi consenso entre os pais, as opiniões divergem no tocante ao seu valor educativo. Para muitos a noção de vínculo pode servir para a formação de maus hábitos, tornando os filhos dependentes do dinheiro para que cumpram com suas responsabilidade, talvez por isso optem por não atrelá-la a nenhuma atividade, como cumprimento de atividades domésticas, leitura de livros ou ir bem nos estudos, com receio de que os filhos passem a estudar ou ler apenas por dinheiro e que no futuro tornem-se dependentes de dinheiro para realizarem as responsabilidades, como mostra a UCE seguinte: Não se deve vincular a mesada a nada, porque se fizer isso minhas filhas podem criar um vício de só fazer alguma coisa se tiverem algo para receberem em troca, tudo que fizerem será apenas para ganharem dinheiro (Participante 29, mãe, 41 anos, 2 filhos, II Grau, renda de R $\$ 10.000,00)$.

Em contrapartida, existem pais que concordam com a noção do vínculo, acreditando que este pode ser um estímulo para o cumprimento de atividades, funcionando como um instrumento de recompensa. A próxima UCE exemplifica a importância dada pelos pais acerca da recompensa, mediante o vínculo da mesada com o cumprimento de responsabilidades ou atividades: Para mim a mesada tem que estar vinculada a alguma coisa, deveres domésticos, ir bem na escola, se relacionar com amigos (Participante 1, pai, 33 anos, 1 filho, II Grau, renda de R\$3.200,00).
Furnham (2001) também verificou divergências em relação a se o dinheiro dado à criança deveria ser dependente da conclusão de tarefas domésticas, se os exames escolares deveriam ser recompensados e se o dinheiro deveria ser retido como castigo. Os resultados demonstram que não existiu diferença em relação às variáveis: renda, sexo, idade, escolaridade e número de filhos. Foram encontrados pais de renda média e baixa que concordam e discordam da noção da mesada estar atrelada a atividades. Esses resultados confirmam a existência de variações sociais e culturais acerca do que seria a melhor forma de educar os filhos.

Este fato foi observado em diversos estudos (Lordelo, 2002; Seidl de Moura et al. 2004), que apontam para diferentes crenças parentais concernente a educação de filhos. Essas diferenças variam de contextos culturais e são acompanhadas pela história de vida de cada indivíduo, bem como do meio que o circunda. Mas que devem ser compreendidos como proposto pelo co-construtivismo, dentro do contexto cultural em que ocorre o desenvolvimento, uma vez que o desenvolvimento individual é dirigido pela organização cultural do ambiente, sendo determinado pela relação existente entre o organismo e o ambiente que o rodeia (Valsiner, 2000).

Apesar das diferentes visões sobre a noção de vínculo da mesada a atividades, o discurso dos pais está relacionado à preocupação de ensinarem os filhos a administrarem o dinheiro que recebem. E conforme verificado, os pais por meio de recompensa e sansões vão procurando instalar nos filhos suas crenças sobre economia (Lunt \& Furnham, 1996). Em busca de justificar o uso da mesada como estratégia educativa, muitos pais acabam optando por vincular ou não a mesada a alguma atividade.

O conjunto de conteúdos referentes a "motivos para os pais darem dinheiro aos filhos" pertence à classe 3 . Essa classe é composta por 189 UCE, representando $26.62 \%$ do total das UCE analisadas. A análise das variáveis descritivas permite caracterizá-las como sendo produzida nos grupos de pais de renda baixa, que possuíam o II Grau, 4 a 6 filhos, e renda familiar de $\mathrm{R} \$ 500,00$ a $\mathrm{R} \$ 1.000,00$, em sua maioria mulheres com menos de 30 anos. A maioria dos participantes vive em situações de moradia bem precárias e trabalham como, domésticas, cozinheiras, vendedoras ou não possuem um emprego fixo, contando com a renda do marido ou companheiro para o sustento da família. 
Algumas palavras da classe 3 expressam conteúdos que revelam a justificativa dos pais para darem mesada aos filhos. São elas: pedir, precisando, amigos, sentir, emprestado (ver Figura 2). Dentre as justificativas que levam os pais a darem mesada aos filhos está a questão da inserção social e status social. Os pais não querem que os filhos se sintam mal no meio dos amigos e por isso dão dinheiro aos filhos. Na fala dos pais, pode ser observada a crença da necessidade de inserir o filho no meio social através do dinheiro e a importância dada pelos pais para a necessidade dos filhos comprarem o que os amigos compram. Tal conteúdo pode ser identificado na UCE que exemplificam a classe. Por exemplo: Eu dou dinheiro para os meus filhos, para que não se sintam menos importantes $e$ não se sintam mal. É importante também dar dinheiro para os filhos a fim de que não criem o hábito de se aproveitarem sempre dos amigos (Participante 17, mãe, 35 anos, 2 filhos, II Grau, renda de R $\$ 1.300,00)$.

É interessante ressaltar que a única classe que dentre os motivos ressaltados para dar dinheiro aos filhos destacou a questão do status social foi a classe 3. Esta crença dos pais de darem dinheiro aos filhos para que estes não fiquem a par do contexto social em que vivem faz com que o dinheiro para esses funcione como um instrumento proporcionador de status social e de integração dos filhos ao contexto que o cercam. Este é um aspecto ainda não verificado na literatura sobre o tema, mas que reforça a relação entre as crenças parentais e o contexto cultural dos sujeitos. É muito provável que os pais tenham essa crença por sentiremse a par da sociedade geral devido suas condições financeiras, uma vez que utilizam em suas verbalizações a questão de dar dinheiro aos filhos afim de que estes não se sintam menos, inferiores ou mal em relação aos demais. Parecem utilizar a mesada como estratégia para que os filhos não tenham o mesmo sentimento que eles próprios, lutando para que os filhos sintam-se de fato numa condição superior, como mostra a verbalização a seguir: Dou dinheiro porque sei que meus filhos vão se sentir mal vendo seus colegas comprarem as coisas se eles não tiverem dinheiro para comprarem também, e como são apenas crianças vão se sentir mal igual a gente que é pai se sente (Participante 11, pai, 53 anos, 5 filhos, I Grau, renda e $\mathrm{R} \$ 400,00)$.

Outro motivo que pode ser verificado na UCE acima e que se relaciona com um dos aspectos educacionais da mesada e é de âmbito sociocultural, refere- -se à preocupação dos pais com a formação de hábitos sadios nos filhos. Os pais alegam que dão dinheiro aos filhos com o objetivo de evitar que estes criem o mau hábito de não tendo dinheiro comecem a aproveitarem-se financeiramente dos amigos. Estas justificativas foram evidenciadas apenas por pais de baixa renda e baixa escolaridade, não sendo comentada por pais de renda média e por pais de maior grau de escolaridade.

A UCE seguinte complementa o aspecto ressaltado na UCE anterior referente à preocupação dos pais com o aspecto educacional da mesada, uma vez que destaca que um dos motivos para darem dinheiro aos filhos é evitar que estes peçam na rua de amigos, ou emprestado de colegas, não correndo o risco de tornarem-se oportunistas. Este aspecto é sociocultural, uma vez que a maioria dos participantes possui baixo nível de instrução e vivem em contextos de muita privação. Os conteúdos desta classe ainda não foram encontrados na literatura e podem ser vistos na UCE a seguir: Porque se os filhos forem sair com os amigos e não tiverem dinheiro vão pedir para os colegas, vão aprender a se aproveitar sempre dos outros e serem oportunistas, isso eu não gosto (Participante 17, mãe, 35 anos, 2 filhos, II Grau, renda de $\mathrm{R} \$ 1.300,00)$.

A preocupação dos pais relacionada à punição de dinheiro no presente, e no futuro como consequência os filhos não optarem por trabalharem fica explícita na seguinte UCE: Se o filho ficar pedindo dinheiro emprestado fica mal acostumado e às vezes nem vai procurar querer conseguir trabalhar, porque pensa sempre em pedir dinheiro emprestado de outras pessoas (Participante 10, mãe, 37 anos, 4 filhos, II Grau, renda de $\mathrm{R} \$ 1.100,00)$.

A justificativa de dar dinheiro aos filhos para que não peçam de outras pessoas não foi citado por pais de renda média e alta escolaridade. Já os pais de baixa renda e menos escolarizados preocuparam-se em dar dinheiro para os filhos, pois não aceitam que eles peçam de ninguém, preocupando-se com a questão dos filhos se sentirem desestimulados a procurar trabalho no futuro, devido ao costume formado na infância de pedir dinheiro emprestado. As respostas demonstram que os pais parecem ter o conhecimento de que exercem influências sobre a educação de seus filhos, por isso os orientam e os disciplinam de variadas formas, para que no futuro possam ter hábitos que julgam adequados. Os pais parecem saber que são os principais agentes de socialização econômica dos seus filhos (Furnham, 2001) e que é durante os anos de for- 
mação dos filhos que a compreensão econômica aumenta (Furnham, 1999), pois estão preocupados em desenvolver hábitos saudáveis nos filhos (como o de não pedir dinheiro de amigos ou na rua e nem emprestado). Becker (1996) afirma que os pais exercem fortes influências em relação às primeiras experiências dos seus filhos e ainda que estas experiências poderão influenciar as escolhas e preferências adultas dos filhos.

Como mostram os resultados, as crenças dos pais parecem ter forte efeito em suas práticas, com medo dos filhos desenvolverem hábitos de pedir emprestado, passam a dar dinheiro aos filhos. Alguns autores (Lightfoot \& Valsiner, 1992; Valsiner, 2000, 2001) expõem que as crenças parecem possuir influências sobre as práticas parentais e fazem parte de uma cultura que está constantemente influenciando e sendo influenciada por essas crenças.

Os resultados demonstraram que os pais compartilham algumas crenças, mas enquanto grupo, se diferenciam em relação aos modelos de educarem os filhos economicamente através da mesada, que seriam os mais susceptíveis as influências do ambiente imediato. A influência do ambiente também foi fator fundamental apontados por Lordelo (2000) e Seidl de Moura et al. (2004) em seus estudos. Semelhante aos estudos de Lordelo (2000), os resultados aqui encontrados indicaram que os pais possuíam a tendência de se comportarem de maneiras diferentes, segundo suas condições de vida (pais de baixa renda dão dinheiro para evitar que os filhos peçam, pais de renda média nem sequer comentam sobre essa questão). A influência da variável renda e escolaridade pode ser confirmada nos resultados sobre a questão dos filhos não pedirem (a maioria dos pais dessa classe só possuem o segundo grau e renda baixa) sendo um diferenciador para que essas crenças sejam mantidas por esse grupo.

Os resultados apresentaram diferenças nos grupos de pais de alta escolaridade e nível econômico médio e pais de baixa escolaridade e baixo nível econômico em relação às crenças sobre a mesada. Nenhum pai de maior escolaridade e nível econômico apresentou como motivo de dar mesada aos filhos evitar que pedissem a terceiros ou status social. Isso reflete que esses pais não parecem sentir-se inferiores aos demais que fazem parte de sociedade. Isto confirma a existência de variações sociais e culturais acerca do que os pais pensam ser o melhor em relação à educação e modos de criação dos seus filhos (Seidl de Moura et al., 2004) por isso é importante o estudo dentro de uma perspectiva sociocultural, do modelo de nicho de desenvolvimento.

O conjunto de conteúdos discursivos isolados pelo software Alceste e denominado: "momento para começar a dar mesada" refere-se à classe 5 . Esta classe foi composta por $160 \mathrm{UCE}$, representando $22.54 \%$ do total das UCE analisadas no conjunto de grupos focais. Nesta classe estão às respostas dos sujeitos acerca de quando deve ser o momento de os pais começarem a dar mesada aos filhos, aparecendo aspectos como idade (adolescência) e a noção do valor do dinheiro. Aparecem também justificativas dos pais em relação ao momento de deixarem de dar a mesada aos filhos.

A análise das variáveis descritivas dessa classe permite caracterizá-la como sendo dos grupos de pais de classe baixa e em sua maioria Homens, que possuíam 4 a 6 filhos e que tinham I e II Grau. Algumas das palavras que contidas nesta classe revela a crença dos pais de que existe uma idade específica ou um período provável para os filhos começarem e deixarem de receber mesada são: pais, ano, começar, dar, idade, oito, sete, maior, parar, filhos (ver Figura 2). E podem ser identificadas nas UCE que exemplificam esta classe: Eu acho que deve existir diferença no momento de dar dinheiro para os filhos. Deve ser dado o dinheiro de acordo com a idade dos filhos, por volta dos sete anos (Participante 23, mãe, 38 anos, 4 filhos, I Grau, renda de $\mathrm{R} \$ 800,00)$.

Furnham (2001) indica que a mesada deveria começar a ser dada por volta dos 6 anos de idade. Nas UCE acima é possível observar que a idade citada pelos pais se aproxima dos 6 anos. Os estudos de Furnham e Thomas (1984) demonstraram que os pais de classe média achavam que a criança deveria receber mesada numa idade mais cedo do que os pais de classe baixa. Os resultados dos estudos de Feather (1991) demonstraram que as crianças mais velhas tinham direito automático ao dinheiro enquanto que para as crianças mais novas o ato de dar dinheiro ocorria conforme o desenvolvimento da independência, sem diferença para os sexos. Entretanto é importante destacar que os estudos citados foram realizados fora do país (países britânicos) em que a situação econômica das pessoas de todas as classes sociais em muito divergem da situação dos moradores brasileiros.

Observa-se na UCE seguinte que alguns pais utilizam não apenas a idade como critério para começar a dar dinheiro aos filhos, mas avaliam o desenvolvimen- 
to de certos conceitos na criança para começarem a dar dinheiro. Estes conceitos envolvem a noção da criança de saber o que quer comprar, noção de como gastar o dinheiro, dentre outras:

Acho que os pais devem começar a dar dinheiro aos filhos quando estes tiverem uma noção de como gastar o dinheiro. Com sete anos, oito anos muitas crianças já sabem como usar o dinheiro, para que serve o dinheiro, como administrar o dinheiro. (Participante 14, mãe, 36 anos, 3 filhos, II Grau, renda de R $\$ 800,00$ )

Outro aspecto verificado nas UCE dessa classe diz respeito ao momento dos pais pararem de dar dinheiro aos filhos. Os pais apontaram além da idade a questão da independência, isso inclui arrumar um emprego, entrar na faculdade, etc. A próxima UCE exemplifica o exposto:

Acredito que os pais devem dar mesada ou dinheiro aos filhos até os filhos atingirem a maior idade, com dezoito anos. A partir da maior idade os pais vão ajudar a critério, mostrar para os filhos que já devem estar inserido no mercado de trabalho... devem parar de dar quando já alcançaram independência financeira, quando entrarem na faculdade. (Participante 1, pai, 33 anos, 1 filho, III Grau, renda de $\mathrm{R} \$ 3.200,00$ )

Ainda outro aspecto relevante nessa classe referese à distinção entre o filho maior e o menor em relação à quantia de dinheiro que devem receber. Os pais concordam com a ideia de que não deve existir discriminação no momento de dar dinheiro aos filhos se estes possuem idades próximas, mas concordam que se existir uma grande diferença de idade entre os filhos, deve ser dado quantia diferente para cada um, conforme a UCE a seguir: Quando a diferença de idade entre os filhos é muito grande acho que o filho maior deve receber mais que o filho menor (Participante 29, mãe, 41 anos, 2 filhos, II Grau, renda de $\mathrm{R} \$ 10.000,00)$.

Os resultados dos estudos de Furnham e Thomas (1984) com pais britânicos foram divergentes dos resultados do presente estudo em relação à distinção de idade para dar mesada. Os autores acima apresentaram que os adultos de classe baixa acreditaram que os meninos deveriam receber mais dinheiro de mesada que as meninas. Os resultados das UCE demonstraram que os pais de baixa renda do presente estudo são a favor da igualdade de dinheiro em relação ao sexo e idade.

\section{CONCLUSÃO}

Em relação ao corpus analisado, obtivemos a crença fundamental da mesada como estratégia educativa. Os pais participantes do presente estudo acreditam que a mesada possui a função de ensinar e educar os filhos para que possam aprender a administrar o dinheiro no futuro, sabendo como gastar e economizar. Os pais acreditam ainda que a mesada poderá ajudar os filhos no desenvolvimento da responsabilidade e no treinamento da independência.

Uma função da mesada verificada e destacada apenas por pais de baixa renda refere-se à importância de darem dinheiro aos filhos a fim de que estes não se sintam mal ou inferior em relação aos seus amigos. A mesada neste contexto passa ter uma função de status e inserção social. Foi verbalizado também por pais de baixa renda a necessidade de darem dinheiro aos filhos para que estes não roubem ou peçam na rua, realidade muito próxima ao convívio desses pais.

Verificou-se que os pais vêem a mesada como um instrumento que pode servir como recompensa, quando é dado após os filhos cumprirem regras ou metas determinadas anteriormente por eles ou servir como instrumento que pode criar maus hábitos. Os hábitos negativos podem ser fomentados quando os filhos se acostumam a receber dinheiro, proveniente da mesada sem esforço algum, isto é, quando recebem a mesada sem que lhes seja imposto nenhuma obrigação ou responsabilidades. Percebe-se que os pais vinculam a mesada ao cumprimento de atividades que deverão ser executadas pelos filhos e que a presença de falhas por parte dos filhos poderá acarretar a retirada da mesma. Verifica-se que a mesada tem uma função de disciplinar, contendo um ingrediente punitivo. Mas, embora este ingrediente punitivo seja real é justificado pelos pais como compondo um dos principais propósitos da mesada: sua função educativa.

Conclui-se ainda que os pais, além de utilizar a mesada como uma estratégia educativa, adotam critérios para iniciarem a dar a mesada aos filhos e para cortarem a mesma, e estão de acordo com a ideia de que deve existir uma idade aproximada para iniciarem o esquema de mesada - a idade mais provável seria entre 6 e 7 anos. Os pais avaliam nos filhos o desenvolvimento de conceitos referentes ao que comprar, como gastar e poupar para iniciarem o esquema de mesada. Foi encontrado também um consenso entre os pais em relação ao momento de parar de dar mesada. Os pais acreditam que o momento para parar de dar mesada está relacionado à independência financeira, 
isto é, quando os filhos já estiverem trabalhando e se sustentando ou quando entrarem na faculdade. Consenso também foi verificado em relação à igualdade de sexo e idade no recebimento da mesada.

Se os pais não estabelecerem regras claras sobre como gastar o dinheiro, os filhos poderão usar o dinheiro irresponsavelmente e consequentemente a educação econômica não poderá acontecer. Lassarre (1996) afirmou que a prática de dar mesada é sinal de educação econômica dentro da família. Furnham (1999) também declarou que os pais usam a mesada como um modo de socializar e educar as crianças. Conclui-se que se os pais não estabelecerem regras claras em relação a como os filhos lidarem com a mesada a educação econômica poderá não acontecer. E mesmo considerando as diferenças em relação às práticas parentais e às funções da mesada, todos os pais têm em comum a crença de que ela é uma estratégia educativa.

\section{REFERÊNCIAS}

Abramovich, R., Freedman, J., \& Pliner, P. (1991). Children and money: Getting an allowance, credit versus cash, and knowledge of pricing. Journal of Economic Psichology, 12, 27-45.

Baelle, A., \& Vlerick, P. (2000). Pocket money and saving behavior of children: A qualitative study. In International Association for Research in Economic Psychology/Society for the Advancement of Behavioral Economics (Eds.), IAREP/SABE 27th Annual Colloquium (pp. 35-39). Baden: IAREP/SABE.

Ballvè, F. D. (2000). A criança e a experiência do consumo: Um estudo etnográfico em uma escola do Rio de Janeiro (Dissertação de mestrado). Universidade Federal do Rio de Janeiro.

Bauer, M., Gaskell, G., \& Allum, N. (2003). Qualidade, quantidade e interesses do conhecimento: Evitando confusões. In M. Bauer \& G. Gaskell (Eds.), Pesquisa qualitativa com texto, imagem e som (pp. 17-36). Petrópolis: Vozes.

Becker, G. S. (1996). Accounting for tastes. Cambridge, MA: Harvard University Press.

Brofenbrenner, U. (1996). A ecologia do desenvolvimento humano: Experimentos naturais e planejados. Porto Alegre: Artes Médicas.

Cram, F., \& Ng, S. H. (1999). Consumer socialization. Applied Psychology, 48, 297-312.

Feather, N. T. (1991). Variables relating to the allocation of pocket money to children: Parental reasons and values. British Journal of Social Psychology, 30, 221-234.

Furnham, A. (1999). The saving and spending habits of young people. Journal of Economic Psychology, 20, 677-697.

Furnham, A. (2001). Parental attitudes to pocket money/allowances for children. Journal of Economic Psychology, 22, 397-422.

Furnham, A., \& Argyle, M. (1998). The psychology of money. London: Routledge.

Furnham, A., \& Thomas, P. (1984). Pocket money: A study of economic education. British Journal of Developmental Psycho$\log y, 2,205-212$.
Gondim, S. M. G. (2002). Grupos focais com técnica de investigação qualitativa: Desafios metodológicos. Paidéia, 12, 149-161.

Harkness, S., \& Super, C. M. (1992). Parental ethnotheories in action. In I. Sigel, A. V. McGillicuddy-DeLisi \& J. J. Goodnow (Eds.), Parental belief systems: The psychological consequences for children (pp. 373-391). Hillsdale, NJ: Lawrence Erlbaum.

Harkness, S., \& Super, C. M. (1996). Parents' cultural belief systems: Their origins, expressions, and consequences. New York: Guilford Press.

Lassarre, D. (1996). Consumer education in French families and schools. In P. Lunt \& A. Furnham (Eds.), Economic socialization (pp. 130-148). Cheltenham, UK: Edward Elgar.

Lauer, I. L., \& Magalhães, C. M. C. (2007). Crenças parentais quanto à mesada (Dissertação de mestrado). Universidade $\mathrm{Fe}$ deral do Pará, Belém.

Lightfoot, C., \& Valsiner, J. (1992). Parental belief system under the influence: Social guidance of the construction of personal cultures. In I. E. Siegel, A. V. McGillicuddy-DeLisi \& J. J. Goodnow (Eds.), Parental belief systems: The psychological consequences for children (pp. 393-414). Hillsdale, NJ: Lawrence Erlbaum.

Lordelo, E. D. R., Fonseca, A. L., \& Araújo, M. L. V. (2000). Responsividade do ambiente de desenvolvimento: Crenças e práticas como sistema cultural de criação de filhos. Psicologia: Reflexão e Crítica, 13, 73-80.

Lunt, P., \& Furnham, A. (1996). Economic socialization: The economic beliefs and beharivours of young people. Cheltenham, UK: Edward Elgar.

Moreira, A. (2000). Valores e dinheiro: Um estudo transcultural das relações entre prioridades de valores e significado do dinheiro para indivíduos (Tese de doutorado). Universidade de Brasília.

Oliveira, D. C., Gomes, A. M. T., \& Marques, S. C. (2005). Análise estatística de dados textuais na pesquisa das representações sociais: Alguns princípios e uma aplicação ao campo da saúde. In M. S. S. Menin \& S. A. Moraes (Eds.), Experiências e representações sociais: Questões teóricas e metodológicas (pp. 157-200). São Paulo: Casa do Psicólogo.

Reinert, M. (1990). Alceste, une méthodologie d'analyse des données textuelles et une application: Aurélia de Gérard de Nerval. Bulletin de Méthologie Sociologique, 26, 24-54.

Seidl de Moura, M. L., Ribas, R. C. R. J., Piccinini, C. A., Bastos, A. C. S., Magalhães, C. M. C., \& Vieira, M. L. (2004). Conhecimento sobre desenvolvimento infantil em mães primíparas de diferentes centros urbanos do Brasil. Estudos de Psicologia (Natal), 9, 421-429.

Valsiner, J. (2000). Culture and human development. London: Sage.

Valsiner, J. (2001). Process structure of semiotic mediation in human development. Human Development, 44, 84-97.

Wronski, A. V. (1999). Repercussões do consumo nas relações familiares infantis (Dissertação de mestrado). Universidade Federal de Santa Catarina, Florianópolis.

Recebido: 01/10/2009 Última Revisão: 12/12/2011 Aceito: 03/01/2012 